\title{
Behaviors and Attitudes Associated With Low Drinking Water Intake Among US Adults, Food Attitudes and Behaviors Survey, 2007
}

Alyson B. Goodman, MD, MPH; Heidi M. Blanck, PhD; Bettylou Sherry, PhD, RD; Sohyun Park, PhD; Linda Nebeling, PhD, MPH, RD; Amy L. Yaroch, PhD

Suggested citation for this article: Goodman AB, Blanck HM, Sherry B, Park S, Nebeling L, Yaroch AL. Behaviors and Attitudes Associated With Low Drinking Water Intake Among US Adults, Food Attitudes and Behaviors Survey, 2007. Prev Chronic Dis 2013;10:120248. DOI: http://dx.doi.org/10.5888/pcd10.120248 通.

PEER REVIEWED

\section{Abstract}

\section{Introduction}

Water is vital for life, and plain water is a calorie-free option for hydration. Increasing consumption of drinking water is a strategy to reduce energy intake and lose or maintain weight; however, information on the characteristics of consumers who drink water is limited. Our objective was to describe the characteristics of people who have a low intake of drinking water and to determine associations between their behaviors and attitudes and their intake of water.

\section{Methods}

We analyzed data from a nationally representative sample of 3,397 US adults who participated in the National Cancer Institute's 2007 Food Attitudes and Behaviors Survey. Multivariable logistic regression was used to identify sociodemographic characteristics and health-related behaviors and attitudes associated with self-reported drinking water intake of less than 4 cups per day.

\section{Results}

Overall, $7 \%$ of adults reported no daily consumption of drinking water, $36 \%$ reported drinking 1 to 3 cups, $35 \%$ reported drinking 4 to 7 cups, and 22\% reported drinking 8 cups or more. The likelihood of drinking less than 4 cups of water daily was significantly higher among participants aged 55 years or older than among those aged 18 to 34 (adjusted odds ratio [AOR], 1.3), among residents of the Northeast than among residents of the South (AOR, 1.4), among participants who consumed 1 cup or less of fruits or vegetables per day than among those who consumed 4.5 cups or more (AOR, 3.0), among participants who did not exercise than among those who exercised 150 minutes or more per week (AOR, 1.7), and among participants who were neither trying to gain nor lose weight than among those trying to lose weight (AOR, 1.3).

\section{Conclusion}

Low drinking water intake was associated with age, region of residence, and several unhealthful behaviors and attitudes. Understanding characteristics associated with low drinking water intake may help to identify populations that could benefit from interventions to help adults drink more water.

\section{Introduction}

Adequate water intake has health benefits and is essential for preventing dehydration; dehydration is associated with adverse health effects such as headache, urolithiasis, and impaired cognition (1). Health risks (eg, dental caries, obesity) associated with intake of high levels of calorically sweetened beverages (eg, regular soda, fruit drinks, sports drinks) decrease when plain drinking water is substituted for these beverages $(1,2)$. Water consumption before meals and the replacement of calorically sweetened beverages with water are associated with lower energy intake, and increased plain water intake among adults is associated with significant weight maintenance or loss (3-9). The Dietary 
Guidelines for Americans 2010 encourages adults to drink water as a healthful means of hydration, and public health organizations and others are bringing this message to communities (10-13).

According to 2005-2008 National Health and Nutrition Examination Survey (NHANES) data, mean plain water intake among US adults (aged $\geq 20$ years) was 4.4 cups for men and 4.3 cups for women (14). Little research has been conducted on the association of individual water consumption practices with diet and meal patterns (15). Although water intake has been associated with individual factors (eg, physical activity, age), little is known about how water intake is related to other food- and health-related behaviors and attitudes (14-17). A comprehensive understanding of how these factors are related to water intake may help identify populations and associated attitudes and behaviors amenable to intervention. For example, clinical or public health messages about water intake could be bundled with messages about associated health behaviors. The purposes of our study were to use a data set with varied information on behaviors and attitudes to quantify daily drinking water intake, to identify sociodemographic and health characteristics associated with low water intake, and to describe the association of food- and health-related behaviors and attitudes with low drinking water intake.

\section{Methods}

We used data for this cross-sectional study from the National Cancer Institute's Food Attitudes and Behaviors (FAB) Survey, a mail-panel survey of US adults conducted from October through December 2007. The FAB Survey was approved by the National Cancer Institute's institutional review board (18).

\section{Participants/recruitment}

FAB participants were US residents aged 18 years or older recruited via quota sampling of households in Synovate's Consumer Opinion Panel $(\mathrm{N}=450,000)$ in the fall of 2006. The FAB survey was first mailed to a stratified random sample of 5,803 adults; 200 additional surveys were mailed later (sample balanced to reflect the US population by region of residence, annual household income, population density, age, and household size); African Americans were oversampled (unweighted response rate, 28\%). In total, 3,418 of 6,003 questionnaires were returned (response rate, $57 \%$ ). For our study, we excluded 167 questionnaires (21 overall incomplete, 23 missing the outcome variable, and 123 missing sociodemographic data), leaving a final study sample of 3,251 respondents. Drinking water intake did not significantly differ between included and excluded respondents. The percentage of respondents with unknown values or missing data for individual exposure variables ranged from less than $0.1 \%$ to $7.0 \%$; we excluded respondents with data missing for a given variable from analyses involving that variable.

\section{Variables}

Daily water intake was determined on the basis of participants' responses to the question, "On average, how many cups of bottled or tap water do you drink each day?" Response options were "none," "1-3 cups," "4-7 cups," and "8 or more cups." For multivariable logistic regression models, we dichotomized water intake as "less than 4" or " 4 or more cups" per day based on the mean water intake (approximately 4.3 cups) among US adults according to 2005-2008 NHANES data $(14,15)$.

Sociodemographic variables were age (18-34 years, $35-54$ years, or $\geq 55$ years), sex, race/ethnicity (non-Hispanic white, non-Hispanic black, or other [including Hispanic, non-Hispanic Asian, American Indian, Native Hawaiian, and mixed race]), region of residence (Northeast, Midwest, South, or West), education level (less than a high school diploma, high school degree, some college, or college degree $)$, and annual household income $(<\$ 20,000$; $\$ 20$,000$\$ 44,999 ;$; 45,000-\$74,999; or $\geq \$ 75,000)$.

Variables describing health- and eating-related characteristics for our primary multivariable model were chosen on the basis of likely or known associations with health status and thought to be associated with water intake: weight status based on body mass index (BMI), calculated from self-reported height and weight (underweight/normal weight [BMI $<25.0 \mathrm{~kg} / \mathrm{m}^{2}$ ], overweight [BMI 25.0 to $<30 \mathrm{~kg} / \mathrm{m}^{2}$ ], obese [BMI $\left.\geq 30 \mathrm{~kg} / \mathrm{m}^{2}\right]$ ) (19); daily fruit and vegetable intake (from a validated 16-item screener [18]), categorized as $\leq 1,>1$ to $<4.5$, or $\geq 4.5$ cups based on recommendations for a 2,00o kilocalorie diet (11); minutes of moderate physical activity per week ( 0,1 to $<150, \geq 150$ ) based on the US Physical Activity Guidelines for adults to get at least 150 minutes of moderate-intensity exercise per week (20); cigarette smoking status (never, former, current); intentions for weight management (neither trying to lose nor gain weight, trying to gain weight, trying to lose weight); hours of television watched on an average day ( $\leq 2,>2$ to $<4, \geq 4$ ); and number of hours of sleep on an average night $(<6,6$ to $<8, \geq 8)$.

We conducted secondary analyses to determine whether the following variables with hypothesized associations with health were related to drinking water intake (while maintaining the parsimony of our multivariate model): how often fruits and vegetables were eaten while growing up (rarely, more than once per week, once daily, more than once daily), whether the primary grocery shopper shops at farmers markets or cooperatives (yes, no), meals eaten per week while watching television (none, $1-4, \geq 5$ meals), fast food intake (none, once/week, more than once/week), meals per week eaten at the table with family or friends (none, $1-4, \geq 5$ ), cups of daily $100 \%$ juice intake (none, $1, \geq 2$ cups), and 
respondents' attitudes about "how often worrying about your health has led you to change the way you ate in the past year" (not at all/a little, somewhat, quite a bit/a lot). Variables based on respondents' agreement with the following: "What I eat doesn't really affect my health," "I don't eat fruits and vegetables as much as I like to because they cost too much," "It's hard for me to purchase fruits and vegetables in my neighborhood," and "I think meals should include some meat" (disagree, neither disagree nor agree, agree).

\section{Statistical analyses}

Data on sex, race/ethnicity, age, education, and annual household income were weighted using 2000 US Census data to create a sample distribution similar to the national distribution. Chi-square tests were used to evaluate the frequency of drinking water intake by exposure variables; significance was set at $P<.05$. Odds ratios (OR) and $95 \%$ confidence intervals (CIs) for variables associated with low water intake ( $<4$ cups daily) were calculated from multivariable logistic regression models. The model we used in our primary analysis consisted of sociodemographic variables and selected health- and eating-related variables. In our secondary analyses, we created separate logistic regression models for each exposure variable that were adjusted for age, sex, race/ethnicity, region of residence, income, and education. All analyses were conducted using SAS version 9.2 (SAS Institute, Inc, Cary, North Carolina).

\section{Results}

Of the 3,251 respondents, $43.7 \%$ drank less than 4 cups of water per day (Table 1). Approximately $7 \%$ reported consuming no drinking water daily, $36 \%$ drank 1 to 3 cups, $35 \%$ drank 4 to 7 cups, and $22 \%$ drank 8 cups or more. On the basis of $\chi^{2}$ tests, daily drinking water intake ( $<4$ vs $\geq 4$ cups) varied significantly by age, race/ethnicity, education level, annual household income, weight status, moderate physical activity, fruit and vegetable intake, smoking status, intentions for weight management, and hours of television watched daily.

Multivariable logistic regression indicated that the likelihood of low drinking water intake ( $<4$ cups/d) was significantly higher among people aged 55 or older (vs aged 18-34), living in the Northeast (vs South), trying to gain weight (vs trying to lose weight), participating in no moderate physical activity and 1 to fewer than 150 minutes per week (vs $\geq 150$ minutes/week), and eating less than 4.5 cups of fruits and vegetables daily (vs $\geq 4.5$ cups/d) (Table 1). Lower odds of drinking less than 4 cups of water per day were observed among respondents of "other" race/ethnicity than among whites and among former smokers than among never smokers.

Results of secondary analyses indicated that drinking water intake differed significantly across many eating-related behaviors ( $\chi^{2}$ test, $P<.05$ ) (Table 2). Adjusted ORs indicate that variables significantly related to greater odds for low drinking water intake were recalling eating fruits once daily or less often while growing up (vs more than once daily), recalling eating vegetables once daily or less often while growing up (vs more than once daily), eating fast food more than once per week (vs none), and eating fewer than 5 dinners per week around a table with family or friends (vs $\geq 5$ dinners/week). Shopping at farmers markets or cooperatives (vs not) and intake of 1 or more cups per day of $100 \%$ juice (vs none) were significantly related to lower odds for low drinking water intake (Table 2).

Greater odds of low drinking water intake were significantly related to various attitudes/beliefs about food and health (Table 3). Factors associated with higher odds for low drinking water intake included replying to survey questions as follows: "agree" or "neither disagree nor agree" that "what I eat doesn't really affect my health" (vs "disagree"); "not at all/a little" or "somewhat" to "How often has worrying about your health led you to change what you ate in the past year?" (vs "quite a bit/a lot"); "agree" or "neither disagree nor agree" that "I don't eat fruits and vegetables as much as I like to because they cost too much" (vs "disagree"); "agree" that "It's hard for me to purchase fruits and vegetables in my neighborhood" (vs "disagree"); and "agree" that "I think meals should include some meat" (vs "disagree”).

\section{Discussion}

Our findings indicated that nearly half of respondents drank less than 4 cups per day of water (ie, bottled or tap water) and that $56 \%$ of respondents reported drinking 4 or more cups of water daily. These results are consistent with those based on 2005-2008 NHANES data, which indicated that US adults consumed an average of 4.3 cups of water per day $(14,15)$. The biologic requirement for water may be met with plain water or via foods and other beverages. Results from previous epidemiologic studies indicate that water intake may be inversely related to volume of calorically sweetened beverages and other fluid intake (4).

Our results indicated that low drinking water intake was associated with many demographic characteristics, including older age. Despite being susceptible to dehydration due to increased prevalence of chronic diseases and the use of multiple medications, older adults have lower fluid consumption primarily due to a decrease in thirst $(1,21)$. Previous studies indicate that water consumption decreases with age; a study of 4,112 US adults by Kant et al found lower plain water intake among older US adults $(15,21,22)$. Kant et al reported no significant differences in water intake by race/ethnicity (15), whereas we found significantly higher intake among respondents in the "other" race/ethnicity category than among whites. The reasons for this association are unclear (FAB was not powered to detect differences 
among subgroups in this diverse category). In a study of 4,292 Florida students in grades 6 through 8, Park et al found significantly lower odds of low drinking water intake among Hispanic/Latino or "other"/non-Hispanic adolescents than among white adolescents (adjusted $\mathrm{OR}=0.79$ and $\mathrm{OR}=0.76$, respectively), results that are similar to those we obtained among adults (23). Although our study found no association between drinking water intake and education or household income in multivariable models, previous studies reported that plain water intake is positively associated with years of education but not associated with poverty-income ratio (15). An analysis of the US Department of Agriculture Nationwide Food Consumption Survey of 1977 found lower tap water intake in the Northeast (1.2 L/d) than in other regions $(1.4 \mathrm{~L} / \mathrm{d})$, possibly due to greater need for water among residents in regions with warm or humid climates (24).

Our findings of associations between water intake and certain behaviors were similar to those found in previous research. Meeting the national recommendation for 150 minutes per week of moderate physical activity was associated with significantly higher drinking water intake in this and a previous study (15), which is not surprising given that physical activity leads to increased hydration needs due to sweating (1). The results of our multivariable regression analysis showed no association between water intake and time spent watching television, which is consistent with results of a study among 3,867 US children and adolescents (25). Our finding that former smokers were likely to drink more water than those who never smoked might be explained by the common practice of encouraging participants in tobacco cessation programs to increase their water intake (26).

Low fruit and vegetable intake, which epidemiologic studies link to higher risk of chronic disease (11), was associated with drinking significantly less water in multivariable regression models. In addition, in models controlled for sociodemographic variables, respondents with unhealthful eating behaviors and attitudes (eg, high fast-food intake) drank significantly less water, whereas healthful eating behaviors and attitudes (eg, shopping at farmers markets) were related to drinking more water. These results, which are consistent with findings from previous epidemiologic studies (14-17), add to a growing body of evidence that drinking water intake is associated with healthful dietary practices and attitudes. Whether drinking water supports these healthful dietary patterns or simply coexists with them is unclear. Nonetheless, this evidence suggests that health educators or health care practitioners aiming to promote increased water intake should keep in mind that low water consumption may be closely tied to other unhealthful behaviors.

In our study, respondents trying to lose weight consumed significantly more water than those trying to gain weight; however, results of a previous study (15) showed no significant difference in water intake among respondents trying to lose weight in the previous year than among those not trying to lose weight. Although there is a known significant negative association between energy intake and water consumption, evidence is less clear about the relationship between BMI and water intake. In our study, BMI and water intake levels were unrelated after models controlled for sociodemographics and health-related variables. There are at least 3 plausible explanations for this lack of association: 1) the self-reported BMI values of survey participants may be lower than the true values because survey respondents underestimated weight and overestimated height $(27,28)$, thus decreasing our ability to detect an association; 2$)$ the cross-sectional data did not allow us to assess whether prior behaviors of survey participants may have contributed to weight gain; and 3) our adjustments for factors closely associated with obesity, such as physical activity level or fruit and vegetable intake, may have masked the bivariate association we found between water intake and BMI.

\section{Study limitations}

FAB data are cross-sectional and the survey results can show only an association between factors, not a causal relationship. The FAB sample was selected from a consumer opinions panel rather than the US population (due to declining response to random-digit-dial telephone surveys); this method is commonly used in other nutrition and health studies such as Styles (18). The response rate of $57 \%$ is similar to other random-digit-dial and consumer opinion mailed surveys; information on nonresponders was not available. To minimize bias, households from the larger consumer opinions panel pool selected for FAB were similar to the US population (by age, household income, geographic region, population density, and household size), and data were weighted using US Census estimates; however, these efforts do not guarantee lack of residual bias due to sample selection or nonresponse (18). FAB oversampled African Americans as part of the study design, but the sample size for "other" racial/ethnic groups was not sufficient for subgroup analyses. Dietary intake estimates were self-reported and may have been over- or underestimated and less accurate than data from surveys such as NHANES. Although the validity of the water intake question in FAB has not been determined, a recent study among adults found no significant difference between water intake that was self-reported on a questionnaire (on which the question was worded similarly to the question on the FAB) and water intake determined through 4-day food intake records $(r=0.7)(29)$. BMI data in FAB are determined on the basis of self-reported weight and height and subject to reporting bias; however, measured and self-reported BMI are highly correlated among adults $(r>0.9)$ (30). Finally, because the FAB data set did not include data about intake of calorically or artificially sweetened beverages, milk, or alcohol, we were unable to assess the relationship between intake of water and these beverages. 


\section{Conclusion}

Approximately $7 \%$ of respondents reported drinking no water daily, and nearly half reported drinking less than 4 cups per day. Low drinking water intake was associated with various unhealthful behaviors, including low levels of physical activity and low levels of fruit and vegetable intake. Models controlling for sociodemographics indicated that attitudes about eating and health, as well as food-related behaviors such as eating meals while watching television, were also related to low drinking water intake. Further studies of population samples with greater ability to assess differences in water intake by race/ethnicity subgroups (eg, Hispanics, Asians) are needed, as is research to learn where people consume drinking water, such as homes, worksites, or community venues. Our results suggest that low drinking water intake is common and is associated with known unhealthful behaviors. Clinical and public health practitioners aiming to help people drink more water should consider low water intake as part of a group of unhealthful behaviors and attitudes.

\section{Author Information}

Corresponding Author: Alyson B. Goodman, MD, MPH, Division of Nutrition, Physical Activity, and Obesity, Centers for Disease Control and Prevention, 4770 Buford Highway, NE, Atlanta, GA 30341, USA, Mailstop K-26. E-mail: agoodman@cdc.gov.

Author Affiliations: Heidi M. Blanck, Bettylou Sherry, Sohyun Park, Centers for Disease Control and Prevention, Atlanta, Georgia; Linda Nebeling, National Cancer Institute, Washington, DC; Amy L. Yaroch, Swanson Center for Nutrition, Omaha, Nebraska.

\section{References}

1. Popkin B, D’Anci K, Rosenberg I. Water, Hydration and Health. Nutr Rev 2010;68(8):439-58. CrossRef 通 PubMed 圈

2. Tate DF, Turner-McGrievy G, Lyons E, Stevens J, Erickson K, Polzien K, et al. . Replacing caloric beverages with water or diet beverages for weight loss in adults: main results of the Choose Healthy Options Consciously Everyday (CHOICE) randomized clinical trial. Am J Clin Nutr 2012;95(3):555-63. CrossRef 芯 PubMed 芯

3. Stookey J, Constant F, Popkin B, Gardner C. Drinking water is associated with weight loss in overweight dieting women independent of diet and activity. Obesity (Silver Spring) 2008;16(11):2481-8. CrossRef 图 PubMed 處

4. Stookey J, Constant F, Gardner C, Popkin B. Replacing sweetened caloric beverages with drinking water is

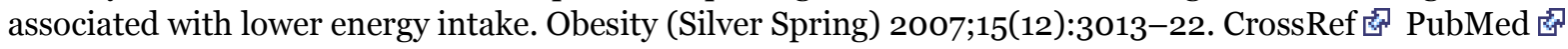

5. Van Walleghen E, Orr J, Gentile C, Davy B. Pre-meal water consumption reduces meal energy intake in older but not younger subjects. Obesity (Silver Spring) 2007;15(1):93-9. CrossRef 圈 PubMed 图

6. Daniels MC, Popkin BM. Impact of water intake on energy intake and weight status: a systematic review. Nutr Rev 2010;68(9):505-21. CrossRef 图 PubMed 图

7. Dennis EA, Dengo AL, Comber DL, Flack KD, Savla J, Davy KP, Davy BM. Water consumption increases weight loss during a hypocaloric diet intervention in middle-aged and older adults. Obesity (Silver Spring) 2010;18 (2):300-7. CrossRef \& PubMed 国

8. Akers JD, Cornett RA, Savla JS, Davy KP, Davy BM. Daily self-monitoring of body weight, step count, fruit/vegetable intake, and water consumption: a feasible and effective long-term weight loss maintenance approach. J Acad Nutr Diet 2012;112:685-92 e2.

9. Duffey KJ, Popkin BM. Shifts in patterns and consumption of beverages between 1965 and 2002. Obesity (Silver Spring) 2007;15(11):2739-47. CrossRef 㐘 PubMed to

10. Popkin BM, Armstrong LE, Bray GM, Caballero B, Frei B, Willett WC. A new proposed guidance system for beverage consumption in the United States. Am J Clin Nutr 2006;83(3):529-42. PubMed 㪍

11. US Department of Agriculture, US Department of Health and Human Services. Dietary Guidelines for Americans 2010. 7th edition. Washington (DC): US Government Printing Office; 2010.

12. Healthy beverages community action kit. Washington (DC): Indian Health Service; 2006.

13. Promoting healthy youth: a parent toolkit for enhancing nutrition and physical activity in schools and at home. Ohio Action for Healthy Kids Association. http://www.ohioactionforhealthykids.org.

14. Sebastian RS, Wilkinson Enns C, Goldman JD. Drinking water intake in the US: what we eat in America, NHANES 2005-2008. Food Surveys Research Group Dietary data brief no. 7; 2011. http://ars.usda.gov/Services/docs.htm?docid=19476. 
15. Kant AK, Graubard BI, Atchison EA. Intakes of plain water, moisture in foods and beverages, and total water in the adult US population - nutritional, meal pattern, and body weight correlates: National Health and Nutrition

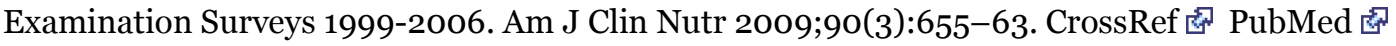

16. Institute of Medicine. Dietary reference intakes for water, potassium, sodium, chloride, and sulfate. Institute of Medicine Panel on Dietary Reference Intakes for Electrolytes and Water, Standing Committee on the Scientific Evaluation of Dietary Reference Intakes. Washington (DC): National Academies Press; 2005.

17. Popkin BM, Barclay DV, Nielsen SJ. Water and food consumption patterns of US adults from 1999 to 2001. Obes Res 2005;13(12):2146-52. CrossRef 图 PubMed 象

18. Erinosho TO, Moser RP, Oh AY, Nebeling LC, Yaroch AL. Awareness of the fruits and veggies - More Matters campaign, knowledge of the fruit and vegetable recommendation, and fruit and vegetable intake of adults in the 2007 Food Attitudes and Behaviors (FAB) Survey. Appetite 2012;59(1):155-60. CrossRef 疋 PubMed 图

19. National Obesity Education Initiative. Clinical guidelines on the identification, evaluation, and treatment of overweight and obesity in adults. Washington (DC): National Heart, Lung, and Blood Institute; 1998.

20. Physical Activity Guidelines Advisory Committee. Physical Activity Guidelines Advisory Committee report, 2008. Washington (DC): US Department of Health and Human Services; 2008.

21. Zizza CA, Ellison KJ, Wernette CM. Total water intakes of community-living middle-old and oldest-old adults. J Gerontol A Biol Sci Med Sci 2009;64(4):481-6. CrossRef 虚 PubMed 逢

22. Jones AQ, Dewey CE, Dore K, Majowicz SE, McEwen SA, Waltner-Toews D. Drinking water consumption patterns of residents in a Canadian community. J Water Health 2006;4(1):125-8. PubMed i

23. Park S, Sherry B, O’Toole T, Huang Y. Factors associated with low drinking water intake among adolescents: the Florida Youth Physical Activity and Nutrition Survey, 2007. J Am Diet Assoc 2011;111(8):1211-7. CrossRef 洛 PubMed 通

24. Drinking water intake. In: Exposures factors handbook. Washington (DC): Environmental Protection Agency; 1997.

25. Kant AK, Graubard BI. Contributors of water intake in US children and adolescents: associations with dietary and meal characteristics - National Health and Nutrition Examination Survey 2005-2006. Am J Clin Nutr 2010;92 (4):887-96. CrossRef 图 PubMed 圈

26. Smoking cessation. Blue Cross Blue Shield of Massachusetts; 2008. http://wwwbluecrossmacom/blueiq/pdfs/83233-smoking-cessation-eipdf.

27. Himes JH. Challenges of accurately measuring and using BMI and other indicators of obesity in children.

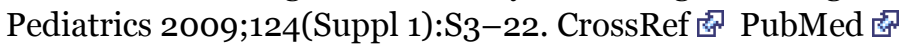

28. Stommel M, Schoenborn CA. Accuracy and usefulness of BMI measures based on self-reported weight and height: findings from the NHANES \& NHIS 2001-2006. BMC Public Health 2009;9:421. CrossRef 图 PubMed 迢

29. Hedrick VE, Comber DL, Estabrooks PA, Savla J, Davy BM. The beverage intake questionnaire: determining initial validity and reliability. J Am Diet Assoc 2010;110(8):1227-32. CrossRef 芯 PubMed 通

30. McAdams MA, Van Dam RM, Hu FB. Comparison of self-reported and measured BMI as correlates of disease markers in US adults. Obesity (Silver Spring) 2007;15(1):188-96. CrossRef 图 PubMed 愢

\section{Tables}

Table 1. Respondents' Characteristics, Reported Daily Drinking Water Intake, and Adjusted Odds of Drinking Less Than 4 Cups Daily, Food Attitudes and Behaviors Survey, United States, 2007

\begin{tabular}{|c|c|c|c|c|c|}
\hline \multirow[b]{2}{*}{ Characteristic } & \multirow[b]{2}{*}{$\begin{array}{l}\text { All, } \\
\%\end{array}$} & \multicolumn{2}{|c|}{$\begin{array}{l}\text { Daily Drinking Water } \\
\text { Intake }\end{array}$} & \multirow[b]{2}{*}{$\begin{array}{c}P \\
\text { Value }^{a}\end{array}$} & \multirow[b]{2}{*}{$\begin{array}{c}\text { AOR }(95 \% \text { CI }) \text { of Drinking }<4 \text { Cups } \\
\text { Water Dailyb }\end{array}$} \\
\hline & & $\begin{array}{l}<4 \text { Cups, } \\
\%\end{array}$ & $\begin{array}{l}\geq 4 \text { Cups, } \\
\%\end{array}$ & & \\
\hline $\begin{array}{l}\text { Total respondents }(n= \\
3,251)\end{array}$ & 100.0 & 43.7 & 56.3 & $<.01$ & NA \\
\hline \multicolumn{6}{|l|}{ Age, y $(n=3,251)$} \\
\hline $18-34$ & 31.3 & 42.9 & 57.1 & .04 & 1 [Reference] \\
\hline
\end{tabular}




\begin{tabular}{|c|c|c|c|c|c|}
\hline \multirow[b]{2}{*}{ Characteristic } & \multirow[b]{2}{*}{$\begin{array}{l}\text { All, } \\
\%\end{array}$} & \multicolumn{2}{|c|}{$\begin{array}{l}\text { Daily Drinking Water } \\
\text { Intake }\end{array}$} & \multirow[b]{2}{*}{$\begin{array}{c}P \\
\text { Valuea }\end{array}$} & \multirow[b]{2}{*}{$\begin{array}{c}\text { AOR }(95 \% \text { CI }) \text { of Drinking }<4 \text { Cups } \\
\text { Water Dailyb }\end{array}$} \\
\hline & & $\begin{array}{l}<4 \text { Cups, } \\
\%\end{array}$ & $\begin{array}{l}\geq 4 \text { Cups, } \\
\%\end{array}$ & & \\
\hline $35-54$ & 35.9 & 41.4 & 58.6 & & $0.9(0.7-1.1)$ \\
\hline$\geq 55$ & 32.8 & 47.0 & 53.0 & & $1.3(1.1-1.7)$ \\
\hline \multicolumn{6}{|l|}{$\operatorname{Sex}(n=3,251)$} \\
\hline Male & 47.4 & 45.1 & 55.9 & \multirow{2}{*}{.18} & 1 [Reference] \\
\hline Female & 52.6 & 42.5 & 57.5 & & $1.0(0.8-1.2)$ \\
\hline \multicolumn{6}{|l|}{ Race/ethnicity $(n=3,251)$} \\
\hline Non-Hispanic white & 77.7 & 44.3 & 55.7 & \multirow{3}{*}{$<.01$} & 1 [Reference] \\
\hline Non-Hispanic black & 11.6 & 47.7 & 52.3 & & $0.9(0.7-1.2)$ \\
\hline Otherc & 10.7 & 34.9 & 65.1 & & $0.6(0.5-0.9)$ \\
\hline \multicolumn{6}{|l|}{ Region $(n=3,251)$} \\
\hline Northeast & 19.1 & 47.0 & 53.0 & \multirow{4}{*}{.06} & $1.4(1.1-1.8)$ \\
\hline Midwest & 22.5 & 45.5 & 54.5 & & $1.1(0.9-1.5)$ \\
\hline South & 38.0 & 43.4 & 56.6 & & 1 [Reference] \\
\hline West & 20.4 & 39.3 & 60.7 & & $1.0(0.7-1.2)$ \\
\hline \multicolumn{6}{|c|}{ Highest education level $(n=3,251)$} \\
\hline $\begin{array}{l}\text { Less than a high school } \\
\text { diploma }\end{array}$ & 13.8 & 50.2 & 49.8 & \multirow{4}{*}{$<.01$} & $1.1(0.8-1.5)$ \\
\hline High school diploma & 31.1 & 45.5 & 54.5 & & $1.0(0.8-1.4)$ \\
\hline Some college & 29.2 & 42.6 & 57.4 & & $1.1(0.9-1.4)$ \\
\hline College degree & 25.9 & 39.4 & 60.6 & & 1 [Reference] \\
\hline \multicolumn{6}{|c|}{ Annual household income, $\$(n=3,251)$} \\
\hline$<20,000$ & 20.6 & 48.9 & 51.1 & \multirow{4}{*}{.04} & $1.2(0.9-1.6)$ \\
\hline $20,000-44,999$ & 31.0 & 43.4 & 56.6 & & $1.0(0.8-1.3)$ \\
\hline $45,000-74,999$ & 22.3 & 42.1 & 57.9 & & $1.0(0.8-1.3)$ \\
\hline$\geq 75,000$ & 26.1 & 41.3 & 58.7 & & 1 [Reference] \\
\hline \multicolumn{6}{|c|}{ Weight status $\left(\mathrm{BMI}, \mathrm{kg} / \mathrm{m}^{2}\right)(\mathrm{n}=3,111)$} \\
\hline $\begin{array}{l}\text { Underweight/normal weight } \\
(<25)\end{array}$ & 32.3 & 46.7 & 53.3 & \multirow{3}{*}{$<.01$} & 1 [Reference] \\
\hline Overweight $(25-<30)$ & 34.1 & 43.7 & 56.3 & & $0.9(0.7-1.2)$ \\
\hline Obese $(\geq 30)$ & 33.6 & 40.6 & 59.4 & & $0.8(0.6-1.0)$ \\
\hline \multicolumn{6}{|c|}{ Intentions for weight management $(n=3,241)$} \\
\hline Trying to lose weight & 57.2 & 39.6 & 60.4 & \multirow{3}{*}{$<.01$} & 1 [Reference] \\
\hline Neither trying to lose nor gain & 39.4 & 48.9 & 51.1 & & $1.3(1.0-1.6)$ \\
\hline Trying to gain weight & 3.4 & 55.3 & 44.7 & & $1.7(1.1-2.8)$ \\
\hline \multicolumn{6}{|c|}{ Moderate physical activity, $\min / \mathrm{wk}(\mathrm{n}=3,119)$} \\
\hline 0 & 31.2 & 53.3 & 46.7 & \multirow{3}{*}{$<.01$} & $1.7(1.4-2.1)$ \\
\hline $1-<150$ & 21.4 & 45.4 & 54.6 & & $1.5(1.2-1.9)$ \\
\hline$\geq 150$ & 47.4 & 37.9 & 62.1 & & 1 [Reference] \\
\hline
\end{tabular}




\begin{tabular}{|c|c|c|c|c|c|}
\hline \multirow[b]{2}{*}{ Characteristic } & \multirow[b]{2}{*}{$\begin{array}{l}\text { All, } \\
\%\end{array}$} & \multicolumn{2}{|c|}{$\begin{array}{l}\text { Daily Drinking Water } \\
\text { Intake }\end{array}$} & \multirow[b]{2}{*}{$\begin{array}{c}P \\
\text { Valuea }\end{array}$} & \multirow[b]{2}{*}{$\begin{array}{c}\text { AOR }(95 \% \text { CI }) \text { of Drinking }<4 \text { Cups } \\
\text { Water Dailyb }\end{array}$} \\
\hline & & $\begin{array}{l}<4 \text { Cups, } \\
\%\end{array}$ & $\begin{array}{l}\geq 4 \text { Cups, } \\
\%\end{array}$ & & \\
\hline \multicolumn{6}{|c|}{ Fruit and vegetable intake, cups/d $(n=3,201)$} \\
\hline$\leq 1$ & 24.3 & 59.4 & 40.6 & \multirow{3}{*}{$<.01$} & $3.0(2.2-4.0)$ \\
\hline$>1-<4.5$ & 57.8 & 41.4 & 58.6 & & $1.6(1.2-2.0)$ \\
\hline$\geq 4.5$ & 17.9 & 30.2 & 69.8 & & 1 [Reference] \\
\hline \multicolumn{6}{|c|}{ Cigarette smoking status $(n=3,187)$} \\
\hline Never & 50.1 & 42.4 & 57.6 & \multirow{3}{*}{$<.01$} & 1 [Reference] \\
\hline Former & 24.9 & 39.1 & 60.9 & & $0.7(0.6-0.9)$ \\
\hline Current & 25.0 & 51.2 & 48.8 & & $1.1(0.9-1.4)$ \\
\hline \multicolumn{6}{|c|}{ Hours of television watched on average day $(n=3,160)$} \\
\hline$\leq 2$ & 43.5 & 41.8 & 58.2 & \multirow{3}{*}{$<.01$} & 1 [Reference] \\
\hline$>2-<4$ & 31.6 & 41.5 & 58.5 & & $0.9(0.8-1.1)$ \\
\hline$\geq 4$ & 24.9 & 48.8 & 51.2 & & $1.2(1.0-1.6)$ \\
\hline \multicolumn{6}{|c|}{ Hours of sleep on an average night $(n=3,022)$} \\
\hline$<6$ & 13.8 & 44.6 & 55.4 & \multirow{3}{*}{.91} & $1.1(0.8-1.4)$ \\
\hline 6 to $<8$ & 56.9 & 43.4 & 56.6 & & 1 [Reference] \\
\hline$\geq 8$ & 29.3 & 43.5 & 56.5 & & $0.9(0.8-1.1)$ \\
\hline
\end{tabular}

Abbreviations: AOR, adjusted odds ratio; CI, confidence interval; NA, not applicable; BMI, body mass index.

a Chi-square tests were used for each variable to examine differences across categories.

b The final logistic regression model included variables in 1 model to adjust for possible confounders and included a sample of 2,635 adults with complete data for all variables.

c Of the total study sample (3,251), 5\% were Hispanic, 2\% Asian, 3\% American Indian/Native Hawaiian, and 1\% mixed race.

Table 2. Eating-Related Behaviors, Reported Daily Drinking Water Intake, and Adjusted Odds of Drinking Less Than 4 Cups Daily, by Respondents' Preferences, Food Attitudes and Behaviors Survey, United States, 2007

\begin{tabular}{|c|c|c|c|c|c|}
\hline \multirow[b]{2}{*}{$\begin{array}{l}\text { Eating-Related } \\
\text { Behavior }\end{array}$} & \multirow[b]{2}{*}{$\begin{array}{l}\text { All, } \\
\%\end{array}$} & \multicolumn{3}{|c|}{ Daily Drinking Water Intake } & \multirow[b]{2}{*}{$\begin{array}{c}\text { Adjusted OR ( } 95 \% \text { CI) of Drinking }<4 \\
\text { Cups Dailyb }\end{array}$} \\
\hline & & $\begin{array}{l}<4 \text { cups, } \\
\%\end{array}$ & $\begin{array}{l}\geq 4 \text { cups, } \\
\%\end{array}$ & $\begin{array}{c}P \\
\text { Valuea }\end{array}$ & \\
\hline \multicolumn{6}{|c|}{ How often fruit eaten while growing up $(n=3,215)$} \\
\hline Rarely & 11.5 & 52.3 & 47.7 & \multirow{4}{*}{$<.01$} & $1.8(1.4-2.4)$ \\
\hline More than once/week & 36.0 & 48.3 & 51.7 & & $1.6(1.3-2.0)$ \\
\hline Once daily & 31.2 & 40.3 & 59.7 & & $1.2(1.0-1.5)$ \\
\hline More than once daily & 21.3 & 36.1 & 63.9 & & 1 [Reference] \\
\hline \multicolumn{6}{|c|}{ How often vegetables eaten while growing up $(n=3,226)$} \\
\hline Rarely & 4.7 & 49.6 & 50.4 & \multirow{4}{*}{$<.01$} & $1.6(1.1-2.4)$ \\
\hline More than once/week & 20.0 & 53.1 & 46.9 & & $1.9(1.5-2.4)$ \\
\hline Once daily & 43.3 & 43.5 & 56.5 & & $1.3(1.1-1.6)$ \\
\hline More than once daily & 32.0 & 37.3 & 62.7 & & 1 [Reference] \\
\hline
\end{tabular}




\begin{tabular}{|c|c|c|c|c|c|}
\hline \multirow[b]{2}{*}{$\begin{array}{l}\text { Eating-Related } \\
\text { Behavior }\end{array}$} & \multirow[b]{2}{*}{$\begin{array}{l}\text { All, } \\
\%\end{array}$} & \multicolumn{3}{|c|}{ Daily Drinking Water Intake } & \multirow[b]{2}{*}{$\begin{array}{c}\text { Adjusted OR ( } 95 \% \text { CI) of Drinking }<4 \\
\text { Cups Dailyb }\end{array}$} \\
\hline & & $\begin{array}{l}<4 \text { cups, } \\
\%\end{array}$ & $\begin{array}{l}\geq 4 \text { cups, } \\
\%\end{array}$ & $\begin{array}{c}P \\
\text { Valuea }\end{array}$ & \\
\hline \multicolumn{6}{|c|}{ Primary shopper shops at farmers market/cooperative $(n=3,246)$} \\
\hline No & 80.6 & 45.9 & 54.0 & \multirow{2}{*}{$<.01$} & 1 [Reference] \\
\hline Yes & 19.4 & 34.2 & 65.8 & & $0.6(0.5-0.7)$ \\
\hline \multicolumn{6}{|c|}{ How often meals eaten while watching TV $(n=3,196)$} \\
\hline None & 17.5 & 41.7 & 58.3 & \multirow{3}{*}{.41} & \\
\hline 1-4 meals/week & 33.3 & 42.6 & 57.4 & & $1.1(0.8-1.3)$ \\
\hline$\geq 5$ meals/week & 49.2 & 44.8 & 55.2 & & $1.1(0.9-1.4)$ \\
\hline \multicolumn{6}{|c|}{ Fast Food Intake $(n=3,176)$} \\
\hline None & 29.2 & 39.2 & 60.8 & \multirow{3}{*}{$<.01$} & 1 [Reference] \\
\hline Once/week & 32.6 & 40.7 & 59.3 & & $1.1(0.9-1.4)$ \\
\hline More than once/week & 38.2 & 49.4 & 50.6 & & $1.6(1.3-2.0)$ \\
\hline \multicolumn{6}{|c|}{ Dinners eaten around a table with family or friends $(n=3,145)$} \\
\hline None & 20.9 & 47.5 & 52.5 & \multirow{3}{*}{$<.01$} & $1.3(1.1-1.7)$ \\
\hline 1-4 times/week & 41.2 & 45.1 & 54.9 & & $1.3(1.1-1.5)$ \\
\hline$\geq 5$ times/week & 37.9 & 39.1 & 60.9 & & 1 [Reference] \\
\hline \multicolumn{6}{|c|}{ Daily intake of $100 \%$ juice, cups ( $n=3,238)$} \\
\hline 0 & 21.6 & 51.3 & 48.7 & \multirow{3}{*}{$<.01$} & 1 [Reference] \\
\hline 1 & 62.7 & 43.8 & 56.2 & & $0.8(0.6-0.9)$ \\
\hline$\geq 2$ & 15.7 & 33.3 & 66.7 & & $0.5(0.4-0.6)$ \\
\hline
\end{tabular}

Abbreviations: OR, odds ratio; CI, confidence interval.

a Chi-square tests were used for each variable to examine differences across categories.

b Multivariable logistic regression model included exposure variable and age, sex, race/ethnicity, education, income and region.

Table 3. Attitudes and Beliefs Related to Eating and Health, Reported Daily Drinking Water Intake, and Adjusted Odds Ratios of Drinking Less Than 4 Cups Daily, by Respondents' Attitudes, Food Attitudes and Behaviors Survey, United States, 2007

\begin{tabular}{|c|c|c|c|c|c|}
\hline \multirow[b]{2}{*}{$\begin{array}{l}\text { Eating-Related } \\
\text { Behavior }\end{array}$} & \multirow[b]{2}{*}{$\begin{array}{l}\text { All, } \\
\%\end{array}$} & \multicolumn{3}{|c|}{ Daily Drinking Water Intake } & \multirow[b]{2}{*}{$\begin{array}{c}\text { Adjusted OR (95\% CI) of drinking }<4 \text { cups } \\
\text { dailyb }\end{array}$} \\
\hline & & $\begin{array}{l}<4 \text { cups, } \\
\%\end{array}$ & $\begin{array}{l}\geq 4 \text { cups, } \\
\%\end{array}$ & $\begin{array}{c}P \\
\text { Valuea }\end{array}$ & \\
\hline \multicolumn{6}{|c|}{ What I eat doesn't really affect my health $(n=3,189)$} \\
\hline Disagree & 71.6 & 41.5 & 58.5 & \multirow{3}{*}{$<.01$} & 1 [Reference] \\
\hline $\begin{array}{l}\text { Neither disagree nor } \\
\text { agree }\end{array}$ & 15.6 & 49.1 & 50.9 & & $1.3(1.0-1.6)$ \\
\hline Agree & 12.8 & 48.8 & 51.2 & & $1.2(1.0-1.6)$ \\
\hline \multicolumn{6}{|c|}{ How often has worrying about your health led you to change what you ate in the past year? $(n=3,236)$} \\
\hline Not at all/a little & 46.3 & 47.2 & 52.8 & \multirow{2}{*}{$<.01$} & $1.7(1.4-2.0)$ \\
\hline Somewhat & 31.5 & 44.4 & 55.6 & & $1.5(1.2-1.9)$ \\
\hline
\end{tabular}




\begin{tabular}{|c|c|c|c|c|c|}
\hline \multirow[b]{2}{*}{$\begin{array}{l}\text { Eating-Related } \\
\text { Behavior }\end{array}$} & \multirow[b]{2}{*}{$\begin{array}{l}\text { All, } \\
\%\end{array}$} & \multicolumn{3}{|c|}{ Daily Drinking Water Intake } & \multirow[b]{2}{*}{$\begin{array}{c}\text { Adjusted OR (95\% CI) of drinking }<4 \text { cups } \\
\text { dailyb }\end{array}$} \\
\hline & & $\begin{array}{l}<4 \text { cups, } \\
\%\end{array}$ & $\begin{array}{l}\geq 4 \text { cups, } \\
\%\end{array}$ & $\underset{\text { Valuea }^{\mathbf{P}}}{P}$ & \\
\hline Quite a bit/a lot & 22.2 & 35.5 & 64.5 & & 1 [Reference] \\
\hline \multicolumn{6}{|c|}{ I don't eat fruits and vegetables as much as I like to because they cost too much $(n=3,211)$} \\
\hline Disagree & 45.9 & 40.3 & 59.7 & \multirow{3}{*}{$<.01$} & 1 [Reference] \\
\hline $\begin{array}{l}\text { Neither disagree nor } \\
\text { agree }\end{array}$ & 23.7 & 46.7 & 53.3 & & $1.3(1.1-1.6)$ \\
\hline Agree & 30.3 & 46.9 & 53.1 & & $1.3(1.1-1.6)$ \\
\hline \multicolumn{6}{|c|}{ It's hard for me to purchase fruits and vegetables in my neighborhood $(n=3,205)$} \\
\hline Disagree & 76.8 & 42.8 & 57.2 & \multirow{3}{*}{.15} & 1 [Reference] \\
\hline $\begin{array}{l}\text { Neither disagree nor } \\
\text { agree }\end{array}$ & 12.1 & 44.6 & 55.4 & & $1.0(0.8-1.3)$ \\
\hline Agree & 11.1 & 48.9 & 51.1 & & $1.3(1.0-1.6)$ \\
\hline \multicolumn{6}{|c|}{ I think meals should include some meat $(n=3,189)$} \\
\hline Disagree & 15.9 & 37.8 & 62.2 & \multirow{3}{*}{$<.01$} & 1 [Reference] \\
\hline $\begin{array}{l}\text { Neither disagree nor } \\
\text { agree }\end{array}$ & 22.5 & 38.0 & 62.0 & & $1.0(0.8-1.3)$ \\
\hline Agree & 61.6 & 47.3 & 52.7 & & $1.5(1.2-1.8)$ \\
\hline
\end{tabular}

Abbreviations: OR, odds ratio; CI, confidence interval.

a Chi-square tests were used for each variable to examine differences across categories.

b The multivariable logistic regression model included 1 exposure variable and age, sex, race/ethnicity, education, annual household income, and region.

\section{Comment on this article at PCD Dialogue}

Learn more about PCD's commenting policy

The opinions expressed by authors contributing to this journal do not necessarily reflect the opinions of the U.S. Department of Health and Human Services, the Public Health Service, the Centers for Disease Control and Prevention, or the authors' affiliated institutions.

The RIS file format is a text file containing bibliographic citations. These files are best suited for import into

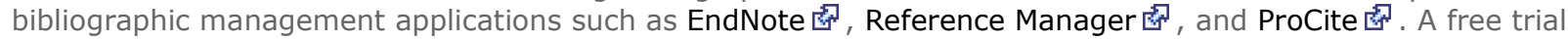
download is available at each application's web site.

For Questions About This Article Contact pcdeditor@cdc.gov

Page last reviewed: April 25, 2013

Page last updated: April 25, 2013

Content source: National Center for Chronic Disease Prevention and Health Promotion

Centers for Disease Control and Prevention 1600 Clifton Rd. Atlanta, GA 30333, USA

80o-CDC-INFO (800-232-4636) TTY: (888) 232-6348 - Contact CDC-INFO 